\title{
Irrigação Automatizada para Cultivo de Açaí em Terra Firme Utilizando a Plataforma Arduino: Uma Solução para Agricultura Familiar
}

DOI: 10.37702/2175-957X.COBENGE.2021.3497

Yago Gomes da Conceição - yagogc.ee@gmail.com

Universidade Federal do Pará

Rua Getúlio Vargas 4752

68703-110 - Capanema - PA

Bianca de Figueiredo Batista - bianca.fb@outlook.com

Universidade Federal do Pará

Travessa Três Irmãos 1023

68702-100 - Capanema - PA

Resumo: Neste artigo, apresentamos o projeto e implementação de um sistema de irrigação automatizada para auxílio do cultivo de Açaí (Euterpe Oleracea Mart.) em terra firme voltado para agricultura familiar. O modelo foi implementado para suprir a demanda hídrica de aproximadamente 1 ha da cultura, utilizando a plataforma de prototipagem Arduino como controlador e seus módulos complementares de baixo custo. $O$ diferencial desta aplicação é que basta ter 0 estudo da necessidade hídrica da cultura que se deseja implementar a irrigação que o código pode ser facilmente modificado/adaptado para a aplicação desejada. O sistema ainda prevê, por meio de uma tela LCD o acompanhamento de dados temporais e status atual dos setores ativos (status das válvulas solenoides).

Palavras-chave: Automação, Arduino, Açaí, Irrigação 


\section{IRRIGAÇÃO AUTOMATIZADA PARA CULTIVO DE AÇAÍ EM TERRA FIRME UTILIZANDO A PLATAFORMA ARDUINO: UMA SOLUÇÃO PARA AGRICULTURA FAMILIAR}

\section{INTRODUÇÃO}

Dentre as mais variadas necessidades da atualidade, encontram-se aquelas relacionadas ao uso, gestão e consumo de recursos naturais. Todavia, a preocupação dos seres humanos com os recursos naturais e sua eventual escassez não é recente, mas a atual situação da crise econômica mundial, comumente chamada de crise do desenvolvimento (ALTOÉ,2012), despertaram ainda mais a atenção do mundo para a necessidade de gerir melhor os recursos e buscar aumento da produção de uma forma equilibrada.

O interesse pela irrigação no Brasil, emerge em variadas condições de clima, solo, cultura e socioeconômica. A agricultura, além do papel fundamental de produzir alimento para a crescente população do planeta, é peça chave na engrenagem da economia mundial. A busca por melhores resultados, os longos períodos de estiagem e as características de cada cultura, têm feito com que o uso de métodos de irrigação sejam cada vez mais difundidos nos meios rurais (CONCEIÇÃO, 2016), necessitando assim de uma atenção especial nesse setor de desenvolvimento, pois grande quantidade de água pode ser desperdiçada se não houver um controle mais adequado na gestão desses recursos (ALTOÉ,2012). Nesses casos, um sistema de irrigação automatizado permite até mesmo diminuir o período de irrigação em tempos chuvosos otimizando o aproveitamento da água (CONCEIÇÃO, 2016).

Com o avanço da tecnologia, o uso da automação tem aumentado bastante a integração dos serviços e produções no meio agrícola, plantações, hortas, cultivadoras de mudas, com o propósito de melhoria da qualidade do produto, economia, eficiência, comunicação e gerenciamento técnico (CONCEIÇÃO, 2016).

Não existe um sistema de irrigação ideal, capaz de atender satisfatoriamente todas

essas condições e interesses envolvidos. (RESENDE, 1993) Em consequência, deve-se selecionar o sistema de irrigação mais adequado para uma certa condição e para atender os objetivos desejados. O processo de seleção requer a análise detalhada das condições apresentadas, em função das exigências de cada cultura, de forma a permitir a identificação das melhores alternativas. (ANDRADE, 2001)

Um ponto importante é que, antes de começar o processo de seleção de algum método de irrigação, deve-se primeiro determinar se há necessidade de irrigação e se é possível irrigar. Muitos agricultores, impulsionados pela pressão comercial e facilidade de crédito, adquirem sistemas de irrigação sem mesmo verificar se a cultura que querem explorar necessita ou responde à irrigação ou, mesmo se a fonte de água de que dispõem é suficiente para atender a necessidade hídrica da cultura. (ANDRADE, 2001)

Este projeto foi aplicado no interior do estado do Pará no cultivo de aproximadamente 1 hectare (Figura 1) da cultura Açaí (Euterpe Oleracea Mart.). Por ser uma planta cujo fruto é bastante apreciado em todo o território brasileiro, e com sua procura em gradativo crescimento, tem-se a necessidade de cultiva-lo em terra firme.

Portanto, por ser uma espécie predominantemente de áreas ribeirinhas, o seu cultivo em terra firme é o principal desafio, já que a planta necessita de água em abundância para seu desenvolvimento e produção do fruto (VIEIRA, 2018). Assim, percebe-se a necessidade da implantação de um sistema de irrigação que supra a necessidade de água e viabilize o cultivo em terra firme. 
Figura 1 - (a) Visão via satélite da região de implantação do projeto. Imagens de 2017. (b)

Plantação de açaí (Euterpe Oleracea) com 3 anos e 1 mês de plantado.
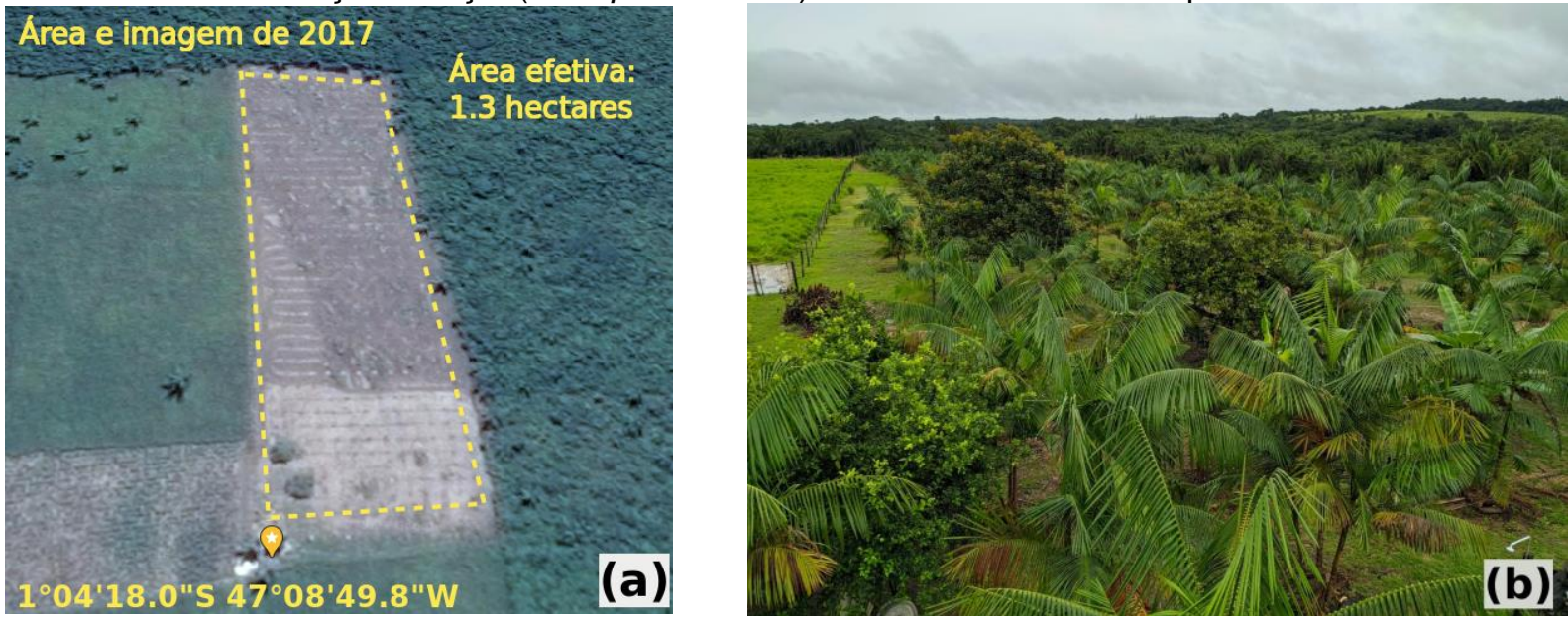

Fonte: (a) Adaptado de https://www.google.com.br/maps/. (b) Próprio autor.

A implementação deste projeto consistiu em adaptar o trabalho (CONCEIÇÃO, 2016) já desenvolvido pelo autor em caráter de proposta de um sistema de automação de um processo de irrigação cuja relação custo-benefício agrega benefícios ao usuário, tais como: praticidade, dinamismo, segurança e simplicidade na execução das tarefas sem deixar de agregar um baixo custo de investimento (já que se trata aqui, de um projeto voltado para agricultura familiar). Atingir o baixo custo sem perder a eficiência do sistema é o objetivo deste sistema, uma vez que os sistemas de automação convencionais não são acessíveis pela agricultura familiar sem comprometer o orçamento.

\section{METODOLOGIA}

Diferentemente do tratado em (CONCEIÇÃO, 2016) que foi uma abordagem de proposta do tema a nível de graduação, aqui foi removido a parte de monitoramento da umidade do solo por meio de sensor substituindo essa etapa simplesmente pela aplicação direta da quantidade de água recomendada (VIEIRA, 2018) pela Embrapa de 10

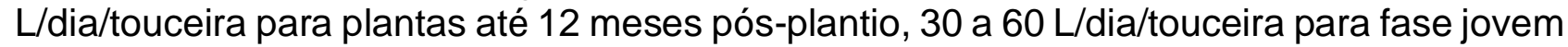
( $2^{\circ}$ ao $5^{\circ}$ ano pós-plantio) e 80 a $100 \mathrm{~L} /$ dia para touceiras adultas (a partir do 6음 ano pósplantio). Reduzindo ainda mais o custo do projeto e a necessidade de manutenções futuras visto que o usuário final não possui conhecimento técnico sobre o sistema.

\subsection{Visão geral do sistema}

O croqui da parte hidráulica é apresentado na Figura 2. Na região de aplicação já estava disponível uma caixa d'água de 2000 litros, mas a bomba hidráulica na época da aplicação não dispunha de potência suficiente para ser ligada diretamente no sistema então optou-se por conectar o sistema diretamente na saída da caixa d'água (Figura 2b). A demanda hídrica do Açaí nos anos iniciais (VIEIRA, 2018) é baixa, então esse ponto não foi um obstáculo, mas atualmente já está instalada uma bomba para alimentar diretamente o sistema.

A área de irrigação foi dividida em 8 setores (Figura 2a) onde cada setor tem sua irrigação controlada por uma válvula solenoide de 1" operando em 24VAC. Toda tubulação principal é de 1" e após a válvula passa a ser tubos PELBD (Polietileno de Baixa Densidade) para irrigação de $16 \mathrm{~mm}$. 
Figura 2 - (a) Visão geral e sintetizada da configuração utilizada em campo. (b) Detalhe da coluna d'água disponível e da boia elétrica posicionada no interior da caixa d'água.

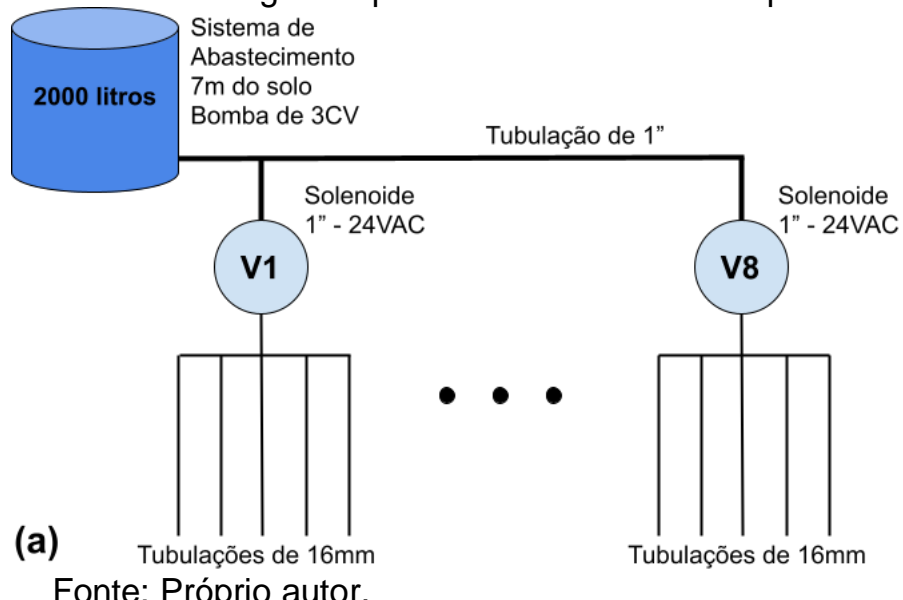

(A) Saída de água para as válvulas

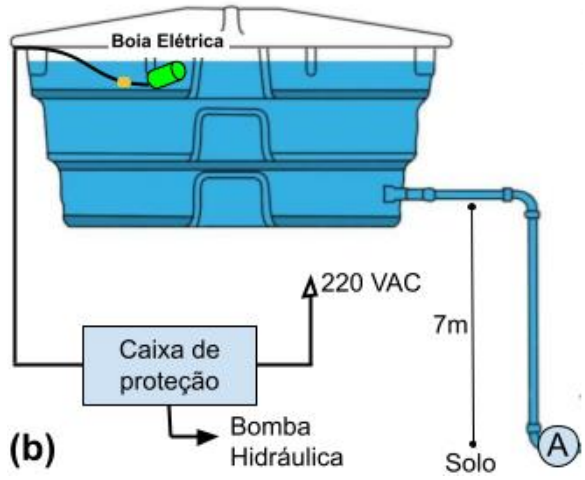

Fonte: Próprio autor.

\subsection{Desenvolvimento do sistema}

Quanto a programação, o ponto principal do projeto está em setar o tempo de irrigação de cada setor de maneira uniforme tomando como base a repetição do ciclo a cada 24h. Inseriu-se então o valor de $30 \mathrm{~min}$ por setor repetindo-se quatro vezes por dia (Figura 3), realizando posteriormente a calibragem do bico gotejador para despejar a quantidade de água necessária com base na idade atual da planta. $O$ tempo adotado pode variar de acordo com a demanda hídrica da cultura e sua idade, bem como o a forma que é inserido água no sistema. Para um sistema que seja alimentado diretamente por uma bomba hidráulica, pode-se adaptar o projeto para uma quantidade maior de intervalos, mas com uma menor duração em cada setor.

Figura 3 - Exemplo de rotina para setar tempo de acionamento da válvula.

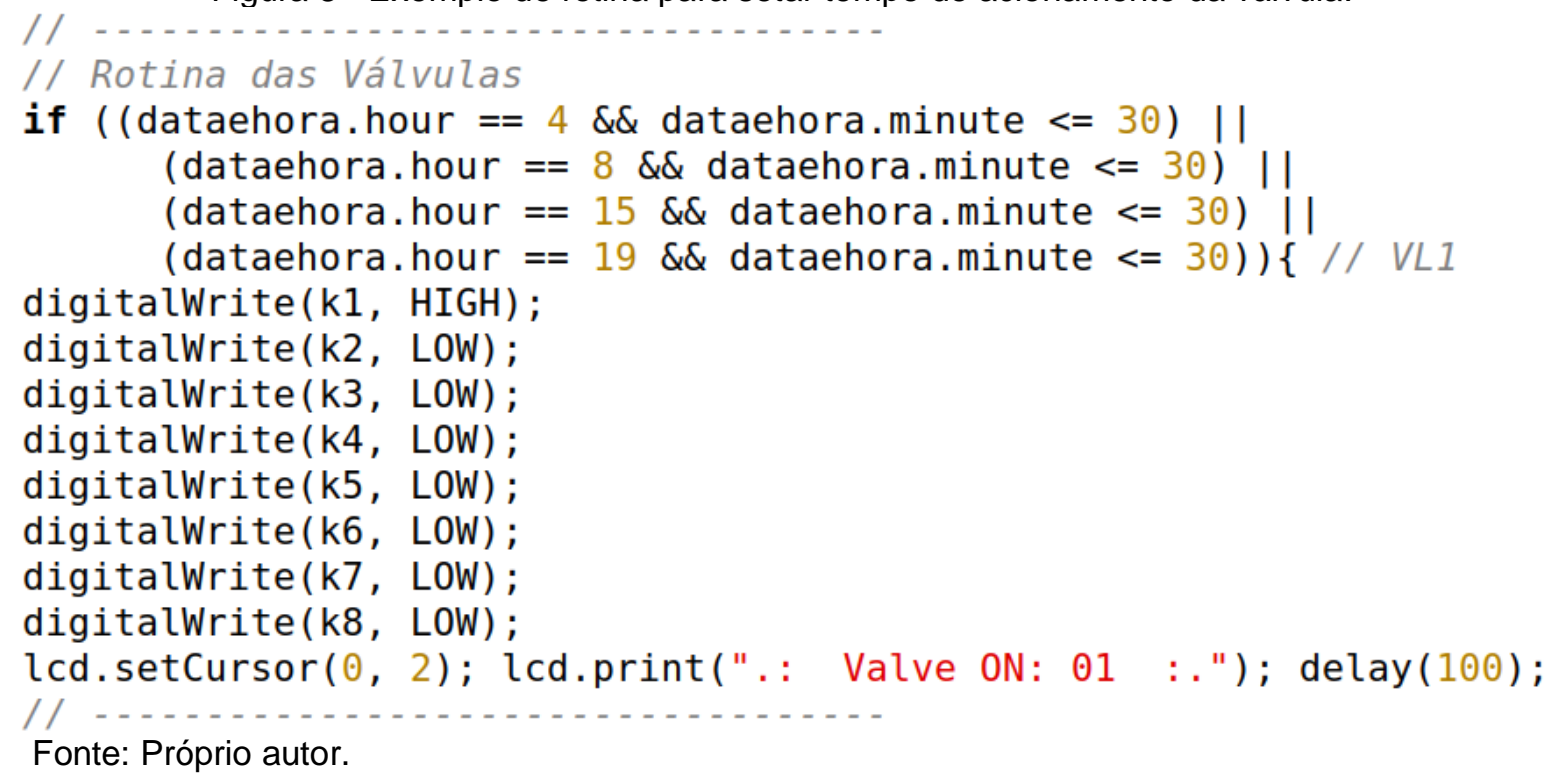

A calibragem do gotejador foi o ponto do projeto que demandou mais tempo de trabalho, uma vez que cada setor possui pouco mais de 60 gotejadores. $O$ processo consistiu em (básica e resumidamente), após o acionamento da válvula (Figura 4a) e a água estabilizada no setor, cronometrar a saída em cada planta afim de regular (ajustando a saída do gotejador - Figura 4b e Figura 4c) a vazão para 10 litros a cada 2 horas (se a faze atual da planta fosse de até 1 ano, por exemplo). 
Figura 4 - (a) Modelo da válvula solenoide utilizado no projeto. (b) Gotejador utilizado na plantação. (c) Detalhe do gotejador.
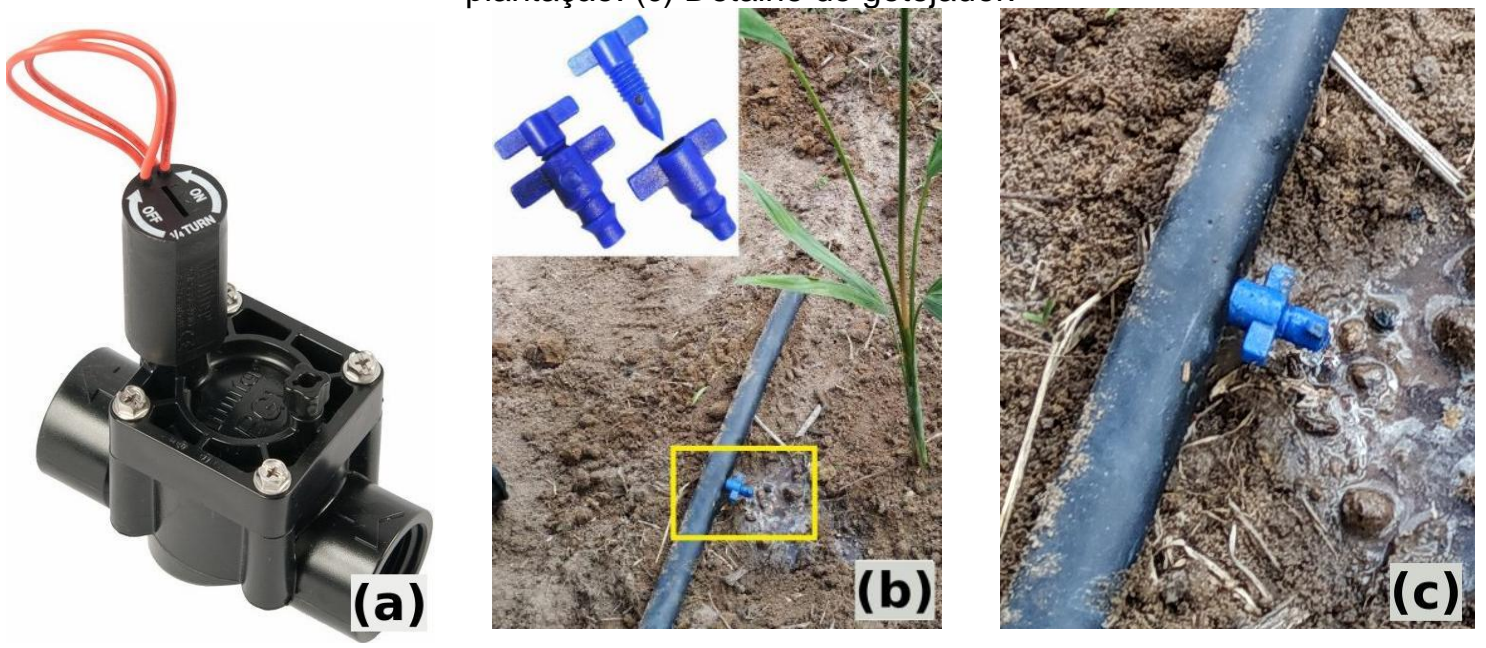

Fonte: (a) Adaptado de https://casairriga.com.br/produto/valvula-solenoide-hunterpgv-1-irrigacaoautomatica-jardim-aspersor/. (b) Próprio autor. (c) Próprio autor.

Para o controle do sistema foi utilizado a plataforma de prototipagem Arduíno Mega (Figura 5a), que utiliza uma linguagem baseada em $\mathrm{C} / \mathrm{C}_{++}$, composta por hardware e software livre (ARDUINO, 2021). Para o acionamento de cada válvula um módulo com 8 relés (Figura $5 \mathrm{~b}$ ) foi adaptado para o sistema. Para a aquisição de dados de tempo a ser utilizado na lógica de acionamento das válvulas um módulo RTC DS1307 (Figura 5c) foi adicionado ao setup, ele possui entrada para bateria, o que permite manter os dados temporais registrado mesmo em caso de falta de energia possibilitando que os dados adquiridos pelo controlador não sejam afetados. Já para alimentação utilizou-se um transformador (Figura 5d) abaixador de 24 VAC com capacidade até $500 \mathrm{~mA}$, esse dispositivo deve ser escolhido de acordo com a recomendação do fabricante de cada válvula.

Figura 5 - (a) Arduino Mega chip ATmega2560-16AU. (b) Módulo relé de 8 portas. (c) Módulo RTC DS1307. (d) Transformador de 24 VAC.
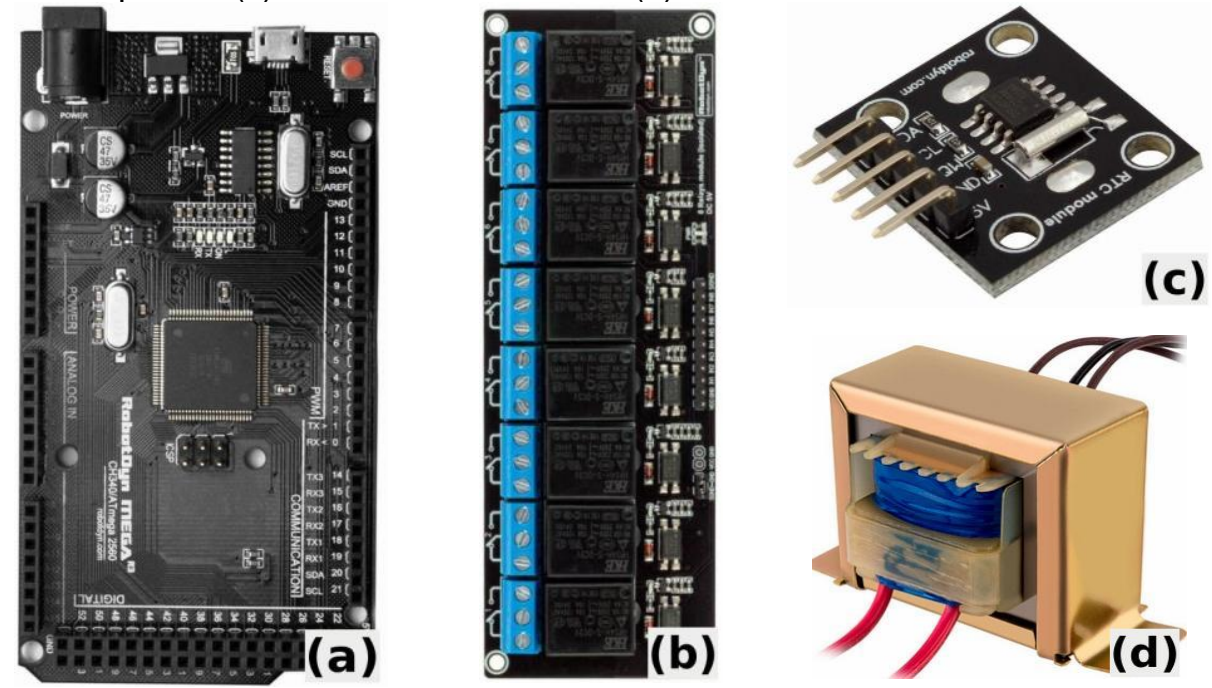

Fonte: Adaptado de https://robotdyn.com/. 
O circuito eletrônico foi elaborado em ambiente virtual, para a realização dos testes necessários e dimensionamento do painel. Foi utilizando o software Proteus 8 da Labcenter Electronics, trata-se de uma suíte que agrega o ambiente de simulação de circuitos eletrônicos ISIS e o programa para desenho de circuito impresso Ares Professional (PROTEUS, 2021). A etapa seguinte foi a montagem do painel seguindo o esquemático da Figura 6.

Figura 6 - Esquemático completo com todas as ligações do painel de comando.

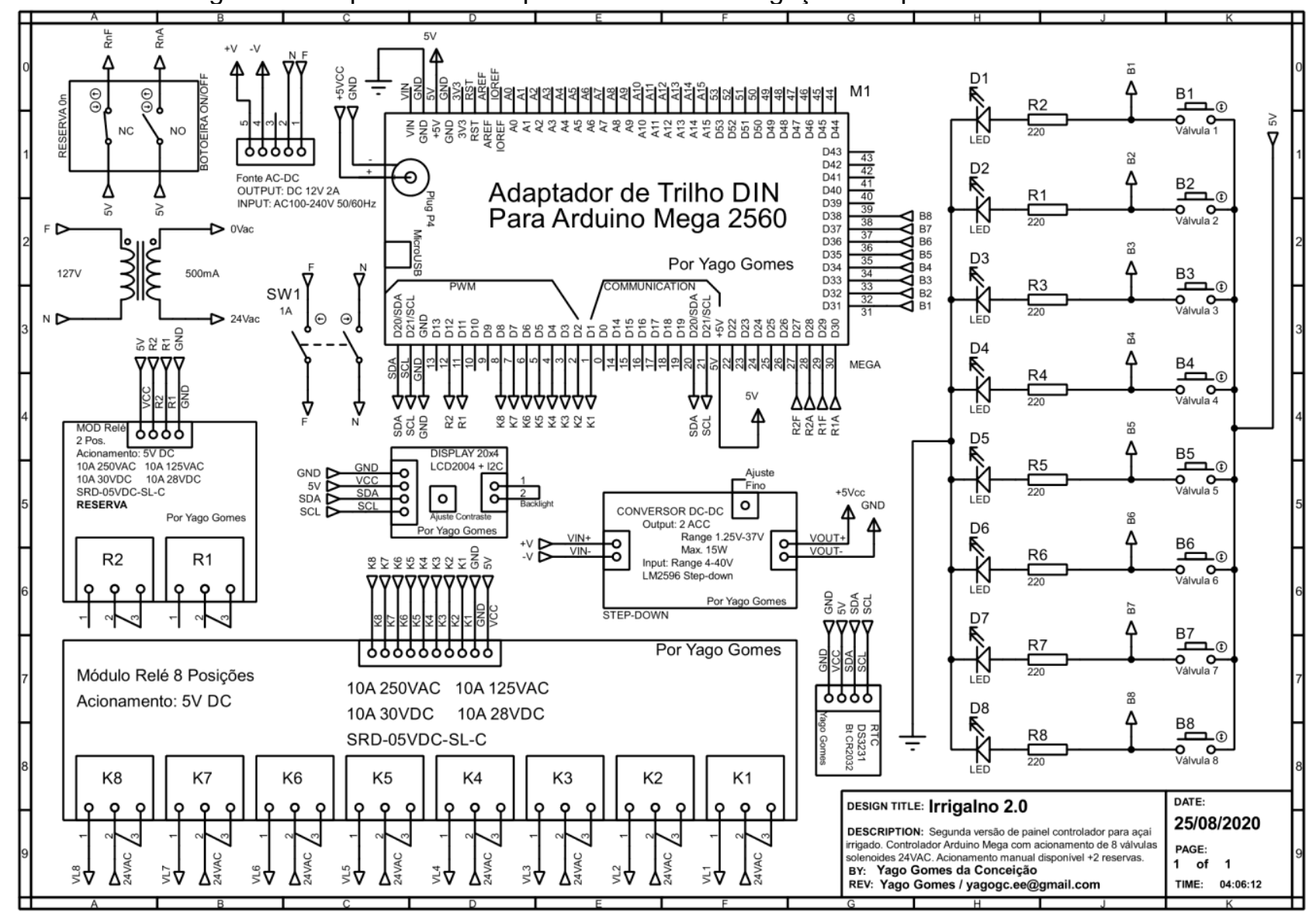

Fonte: Próprio autor.

O projeto conta ainda com um painel de botoeiras onde é possível fazer o acionamento das válvulas independentemente do estado atual do sistema. Isso possibilita facilidade e praticidade em caso de manutenção e/ou ajustes em um dado setor mesmo que esteja em horário de irrigação. Foi adicionado um módulo relé de 2 canais para servir de reserva em caso de expansão ou substituição em caso de defeito em algum dos relés principais.

\subsection{Implementação em campo}

O projeto foi aplicado em uma propriedade privada na cidade de Capanema no interior do estado do Pará. Como fonte de água tem-se disponível poço artesiano com 50 metros de profundidade, sendo qualificado como mais do que suficiente para suprir a demanda hídrica ao longo do ano. O primeiro passo da execução foi instalar todas as válvulas (Figura 7b) e caixas de passagens (Figura 7c) na plantação conforme especificado no projeto (Figura 7a), o que também demandou bastante cuidado e paciência visto que durante a passagem de centenas de metros de fiação pelos eletrodutos seria bem fácil ligar algo errado e acabar por danificar a central de comando bem como as válvulas (Figura 7b). 
Figura 7 - (a) Exemplo do esquemático de ligação e distribuição das válvulas em campo com as caixas de passagem. (b) Válvula solenoide de 1" devidamente instalada e identificada. (c)

Caixa de passagem instalada com condutores e seus identificadores.
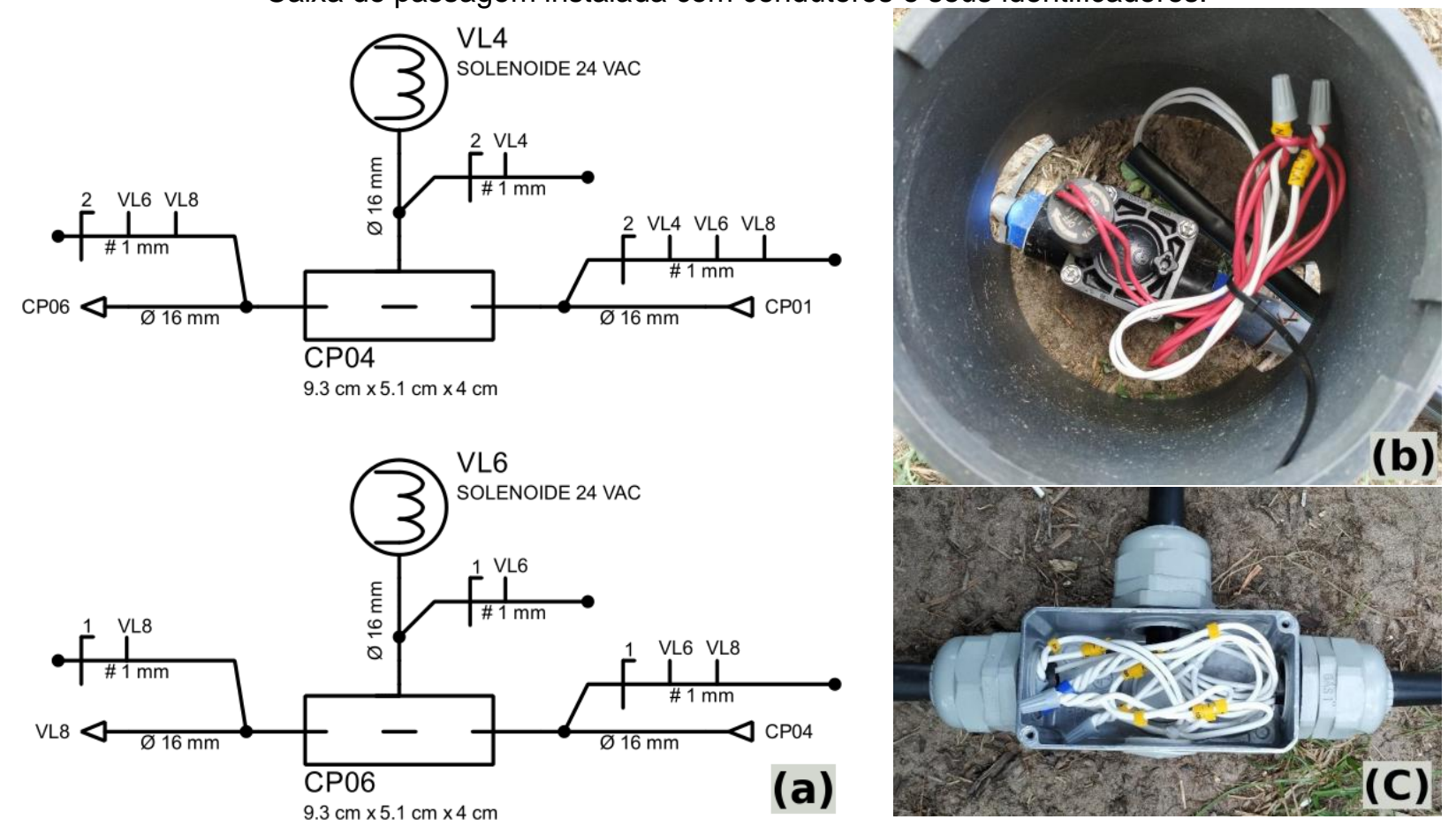

Fonte: Próprio autor.

A Figura 8 mostra o painel de comando construído e fixado próximo a área de abastecimento.

Figura 8 - Caixa de comanda instalada em campo (a) visão externa e (b) visão interna.
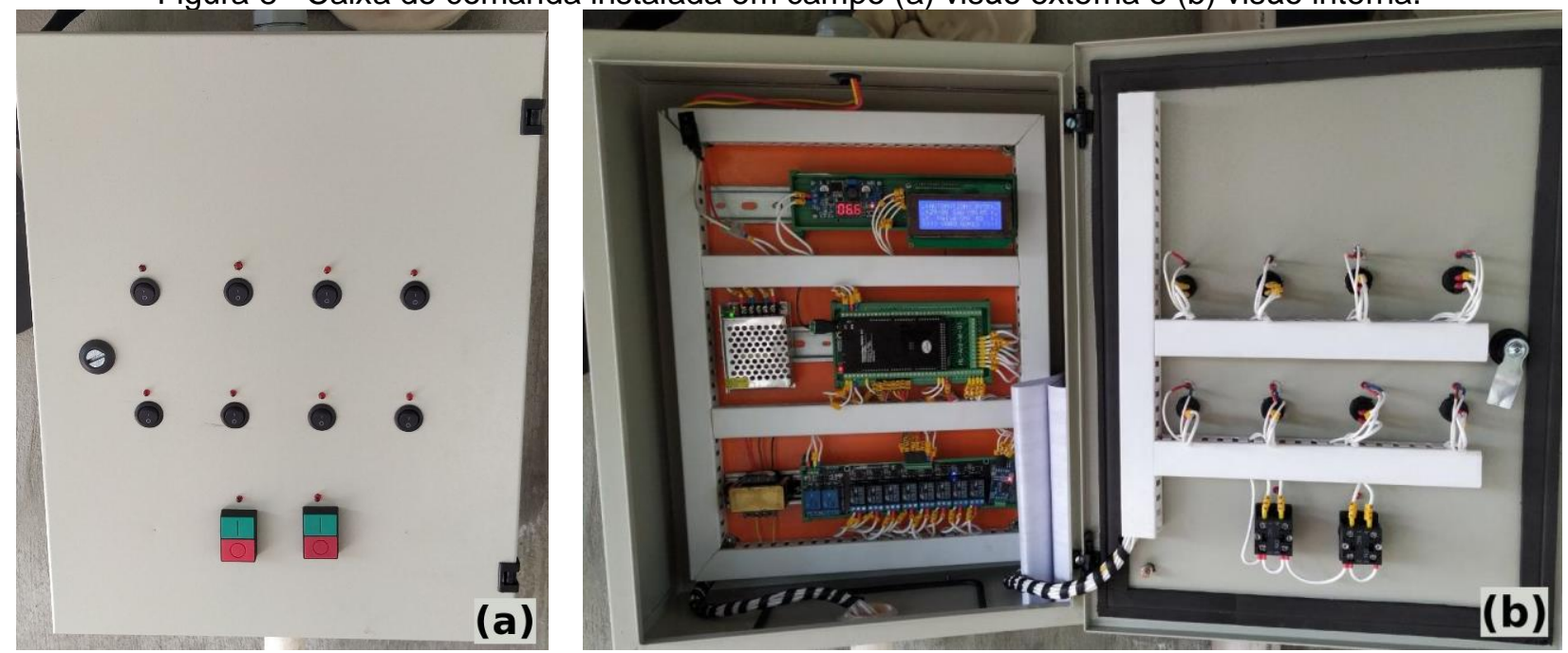

Fonte: Próprio autor.

\section{CONSIDERAÇÕES FINAIS}

Atualmente (4 anos após o plantio do açaí e implementação da irrigação) o sistema ainda se mostra eficiente, tanto na parte da automação (painel, controlador e atuadores) quanto em suprir a demanda hídrica da cultura. De certo que há necessidade de eventuais manutenções como a substituição de um bico gotejador por ter sido danificado em uma 
tarefa de limpeza com maquinário ou (como teve-se conhecimento de uma ocorrência) a troca de do trafo por perda devido a curto-circuito na rede do local.

O sistema atende então sua proposta inicial: oferecer um sistema para controlar de forma competente a demanda hídrica da cultura de Açaí cultivado em terra firme. Oferecendo um projeto para usuários da agricultura familiar com custo mais acessível quando comparado com sistemas já oferecidos comercialmente, mas atingindo os resultados (Figura 9) almejados pelo usuário final.
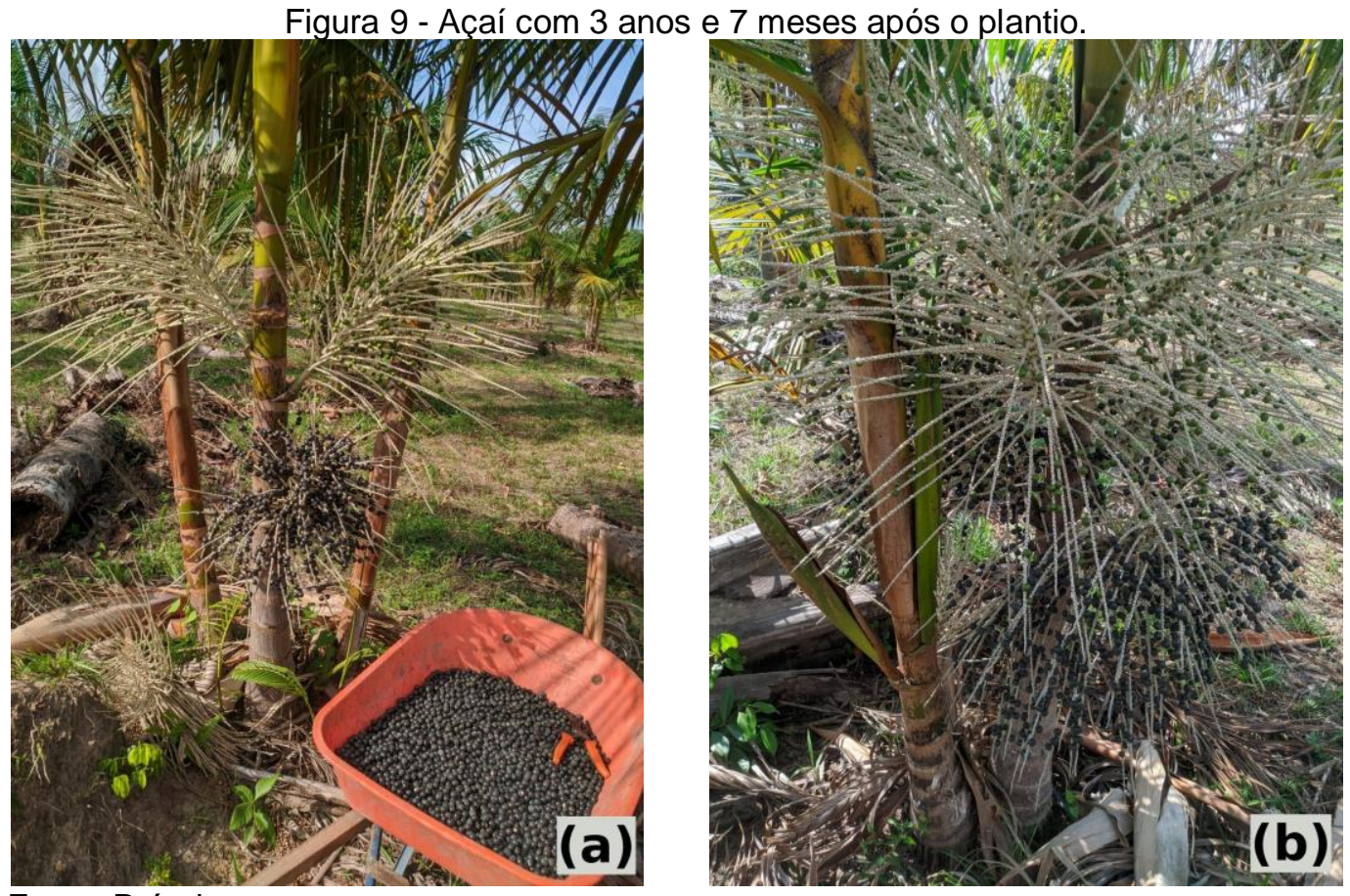

Fonte: Próprio autor.

Este projeto também corroborou com a experiência prática dos autores, uma vez que puderam estar mais próximos da realidade social onde estão inseridos, já que, como engenheiros, tem o papel de desenvolver e aprimorar tecnologias e sistemas que proponham soluções para diversos problemas cotidianos da comunidade em geral, principalmente daqueles que não dispõem de recursos mais elaborados.

O projeto desenvolvido ainda é passivo de otimizações, principalmente a inclusão de atuadores e sensores que possibilitem trabalhos futuros a nível acadêmico. Deve-se ter em mente que a aplicação de técnicas de controle para minimizar as perdas de recursos naturais, e a degradação do meio ambiente, vem crescendo em larga escala, e é dever das instituições de ensino apoiar e incentivar o desenvolvimento tecnológico voltado para tais áreas do conhecimento.

\section{REFERÊNCIAS}

ALTOÉ, Marco Antônio Caixeta. Sistema Automatizado de Irrigação Para Culturas Especificas. 2012. Monografia (Trabalho de Conclusão de Curso) - Curso de Engenharia de Computação. Centro Universitário de Brasília, Brasília, 2012. Disponível em: https://repositorio.uniceub.br/jspui/handle/123456789/3102. Acesso em: 12 abril 2021. 
ANDRADE, C. Seleção do sistema de irrigação. Embrapa Milho e Sorgo. Circular técnica, 2001. Disponível em: https://www.infoteca.cnptia.embrapa.br/bitstream/ doc/485302/1/Circ14.pdf. Acesso em 12 abril 2021.

ARDUINO @. Disponível em: https://www.arduino.cc/. Acesso em: 14 abril 2021.

CONCEIÇÃO, Yago Gomes. Proposta de um sistema automatizado de irrigação por gotejamento utilizando Arduino. 2016. 43 f. Trabalho de Conclusão de Curso (Bacharelado em Engenharia Elétrica) - Campus Universitário de Tucuruí, Universidade Federal do Pará, Campus Tucuruí, 2016. Disponível em: http://bdm.ufpa.br/jspui/handle/prefix/1050. Acesso em: 12 abril 2021.

PROTEUS 8. Labcenter Electronics @ @. Disponível em: https://www.labcenter.com/. Acesso em: 14 abril 2021.

RESENDE, M.; FRANÇA, G. E.; ALVES, VMC. Cultura do milho irrigado. In: Embrapa Milho e Sorgo-Artigo em anais de congresso (ALICE). In: SIMPÓSIO SOBRE FATORES QUE AFETAM A PRODUTIVIDADE DO MILHO E DO SORGO, 1990, Vitória, ES. Cultura do milho: fatores que afetam a produtividade. Piracicaba: POTAFOS, 1993. p. 237-248., 1993. Disponível em: https://www.alice.cnptia.embrapa.br/bitstream/doc/477115 /1/Culturamilho.pdf Acesso em: 14 abril 2021

VIEIRA, A. H. et al. Cultivo do açaizeiro (Euterpe oleracea Martius) no noroeste do Brasil. Embrapa Rondônia - Sistema de Produção (INFOTECA-E), 2018. Disponível em: https://ainfo.cnptia.embrapa.br/digital/bitstream/item/189148/1/Sistema-de-producao-Acai2018.pdf. Acesso em: 14 abril 2021.

\title{
AUTOMATED IRRIGATION FOR AÇAÍ CULTIVATION ON FIRM LAND USING THE ARDUINO PLATFORM: A SOLUTION FOR FAMILY AGRICULTURE
}

\begin{abstract}
In this article, we present the design and implementation of an automated irrigation system to aid the cultivation of Açaí (Euterpe Oleracea Mart.) On dry land aimed at family farming. The model was implemented to supply the water demand of approximately 1 ha of the crop, using the Arduino prototyping platform as a controller and its low-cost complementary modules. The differential of this application is that it is enough to have the study of the water need of the crop that one wants to implement the irrigation that the code can be easily modified / adapted for the desired application. The system also provides, through an LCD screen, the monitoring of temporal data and the current status of the active sectors (status of the solenoid valves).
\end{abstract}

Keywords: Automation, Arduino, Açaí, Irrigation 